\title{
Os desafios éticos da mutilação genital feminina e da circuncisão masculina
}

Dario Palhares ${ }^{1}$, Flávia Squinca ${ }^{2}$

\section{Resumo}

O trabalho aborda os desafios éticos concernentes à mutilação genital feminina e à circuncisão masculina, mostrando similitudes e diferenças. A circuncisão masculina é um procedimento médico para determinadas condições clínicas da saúde genital masculina. Os povos que praticam a mutilação genital feminina também praticam a circuncisão masculina ritualística, sendo que há povos e religiões que praticam a circuncisão masculina sem que haja mutilação genital feminina. A mutilação genital feminina se concentra em bolsões de pobreza, sendo atentatória aos direitos humanos, havendo diversos movimentos mundiais em prol de sua erradicação. A circuncisão masculina pode se associar a complicações bastante sérias, de modo que não é aceitável sua realização sem indicação clínica precisa.

Palavras-chave: Circuncisão feminina. Circuncisão masculina. Cultura. África. Judaísmo-islamismo. Direitos humanos. Violações dos direitos humanos. Medicalização.

\section{Resumen}

\section{Los desafíos éticos de la mutilación genital femenina y de la circuncisión masculina}

Este artículo enfoca los desafíos éticos acerca de la mutilación genital femenina y la circuncisión masculina, demostrando las similitudes y diferencias. La circuncisión masculina es un procedimiento médico para determinadas condiciones clínicas de la salud genital masculina. Los pueblos que practican la mutilación genital femenina también practican la circuncisión masculina ritualista, habiendo pueblos y religiones que practican la circuncisión masculina sin que exista la mutilación genital femenina. La mutilación genital femenina se concentra en zonas de pobreza y ofende a los derechos humanos, habiendo muchos movimientos mundiales en favor de su erradicación. La circuncisión masculina puede estar asociada con complicaciones muy graves, por lo que no es aceptable su realización sin una indicación clínica precisa.

Palabras-clave: Circuncisión femenina. Circuncisión masculina. Cultura. África. Judaísmo-islamismo. Derechos humanos. Violaciones de los derechos humanos. Medicalización.

\section{Abstract \\ Ethical challenges of female genital mutilation and of male circumcision}

This article is about the ethical challenges related to female genital mutilation and male circumcision, by showing similarities and differences. Male circumcision is a medical procedure to some clinical conditions of male genital health. The peoples that carry out the female genital mutilation also carry out together the ritual of male circumcision, but there are peoples and religions that carry out male circumcision without female genital mutilation. Female genital mutilation occurs concentrated in very poor regions and it is against Human Rights, so there are several worldwide movements for its eradication. Male circumcision can be associated to seriously dangerous complications, so that it is not ethically acceptable to be carried out without a precise clinical indication.

Key words: Circumcision, female. Circumcision, male. Culture. Africa. Judaism-islamismo. Human rights. Human rights abuses. Medicalization.

1. Doutor dariompm@unb.br 2. Mestre flavia.squinca@gmail.com - Universidade de Brasília/DF, Brasil.

\section{Correspondência}

Dario Palhares - SQS 313, bloco A, apt 406 CEP 70382-010. Brasília/DF, Brasil.

Declaram não haver conflito de interesse. 
A mutilação genital feminina consiste de um conjunto de práticas realizadas por alguns povos do mundo e apresenta graus distintos de agressividade: o mais leve é a remoção da parte externa do clitóris, passando pela remoção conjunta de clitóris e pequenos lábios, tendo por grau extremo a infibulação, na qual a arquitetura da genitália externa é totalmente refeita, deixando-se apenas um pequeno orifício para a saída de urina e sangue menstrual. Adicionalmente, existem outras práticas menos comuns, como a perfuração clitoridiana ou de lábios com a colocação de adereços, aplicação de ervas adstringentes ou substâncias corrosivas, bem como outras intervenções que modificam a estrutura anatômica ou fisiológica da vagina ${ }^{1}$.

De modo similar, para alguns povos a circuncisão é um ritual de pertencimento ao grupo social. Todos os povos que praticam a mutilação genital feminina também realizam a circuncisão masculina de modo ritualístico, embora haja alguns - como os judeus, determinados grupos muçulmanos e povos rurais de alguns países africanos - que realizam somente a circuncisão masculina, podendo, inclusive, criminalizar as práticas de mutilação genital feminina ${ }^{1}$.

\section{Mutilação genital feminina}

Os rituais de mutilação genital feminina são realizados na menina ou na adolescente, e menos frequentemente na mulher adulta que porventura não tenha sido submetida. Esses procedimentos são antigos na história da humanidade, datando de mais de seis mil anos. Apresentam características de arquétipo, ao terem aparecido em épocas distintas e em povos distintos. Aparentemente, foi um comportamento inicialmente adotado em rituais religiosos do antigo Egito, o qual influenciou os povos próximos, africanos e médio-orientais. Atualmente, a prática persiste de modo sistemático em tribos rurais caracterizadas pelos bolsões de pobreza, analfabetismo e baixo status social da mulher. Além da África e do Oriente Médio, práticas similares foram também descritas em povos indígenas da América do Sul e da Oceania ${ }^{1,2}$.

As sequelas das práticas de mutilação genital para a saúde da mulher são diversas, geralmente decorrentes de problemas na cicatrização ou infecções e suas complicações: lesão extensa do órgão feminino, morte por sepse, hemorragias graves e morte por hemorragia. Esses procedimentos resultam em incidência bastante significativa de complicações e, consequentemente, tornam-se problema endêmico de saúde pública ${ }^{1}$, vez que, na maior parte, são feitos em zonas rurais principalmente por pessoas de baixa escolaridade, sem anestesia, sem assepsia e com instrumentos afiados que podem, inclusive, estar contaminados.

Dentre as consequências da remoção do clitóris e sua relação com as disfunções sexuais nas mulheres submetidas, Degregori ${ }^{1}$ afirma que a clitoridectomia, modalidade prática menos agressiva, não parece se associar a maiores frequências de dispareunia ou anorgasmia, mas, evidentemente, a infibulação, forma mais drástica de mutilação genital feminina, é associada a complicações à saúde por toda a vida, como infecções urinárias de repetição, dor ao coito, dificuldades no parto vaginal.

Mesmo sendo prática cultural milenar, a mutilação genital viola os direitos humanos porque as mulheres são obrigadas a ser submetidas a procedimentos invasivos, dolorosos, potencialmente letais e dos quais não há nenhum benefício à saúde: não se conhecem tratamentos médicos que se assemeIhem ao que é feito nos rituais de mutilação genital feminina. Ou seja, observa-se uma tensão entre uma prática deletéria à mulher, mas que, paralelamente, constitui marca corporal considerada essencial por esses povos para sua legitimação no grupo social ${ }^{3}$. Assim, a mutilação genital feminina revela-se problema exemplar de direitos humanos, saúde pública e igualdade da mulher, encaixando-se, conforme Garrafa e Azambuja ${ }^{4}$, na definição bioética de questões persistentes, haja vista que perpassam vários contextos históricos e culturais, independentemente dos avanços tecnológicos.

Conforme Steiner et $a l^{5}$, a mutilação genital feminina é uma prática emblemática de discriminação social e subalternização da mulher, dentre várias outras criadas socialmente, e cuja essência, permeada por distintos interesses, é a opressão ${ }^{2,3,6}$. Uma coisa são os mecanismos socioeconômicos complexos, outra, uma prática mutilante, deletéria, motivada não apenas no controle e repressão sexual, mas na submissão da mulher no sentido de mostrar, mediante uma cicatriz em seu corpo, sua incapacidade de se relacionar de igual para igual quanto a direitos políticos e econômicos no seio de sua sociedade ${ }^{3}$.

A presença de uma estrutura social injusta no que tange à condição de gênero encontra-se correlacionada às práticas de mutilação genital feminina, mas a desigualdade, por si, não justifica nem valida esses procedimentos ${ }^{6}$. Essas práticas são apenas um modelo de atitudes, dentre vários outros, que as sociedades em geral impõem contra os direitos das mulheres na saúde, educação, trabalho e salários, chegando mesmo à ocorrência do aborto seletivo ${ }^{2}$. 
Contudo, por mais delicado seja o tema, a mutilação genital é muito visível para ser ignorada e afeta miIhões de vidas, justificando-se que a discussão seja tomada não apenas como questão central dos movimentos sociais em prol de sua erradicação ${ }^{2}$, mas também como tema de reflexão bioética.

Nesse segundo aspecto, cabe salientar que, além da discussão, se presta à reflexão bioética ampla acerca da universalidade dos direitos humanos, considerando a contraposição entre direitos individuais e coletivos, abarcando, especificamente, os aspectos relacionados aos direitos culturais. Assim, o objetivo do presente trabalho é discutir e comparar os desafios éticos da mutilação genital feminina e da circuncisão masculina rotineira com o objetivo de estimular a comunidade bioética a encarar essa discussão essencial.

\section{Circuncisão masculina}

O prepúcio é um capuz de pele naturalmente retrátil que recobre a glande e cuja remoção cirúrgica, denominada circuncisão, é um tratamento cientificamente válido para um grupo de condições relativas à saúde genital do homem, tais como fimose, parafimose, balanite crônica, síndrome do excesso de prepúcio. No caso da parafimose, a remoção do prepúcio pode se constituir até mesmo como um procedimento cirúrgico de urgência ${ }^{7}$. Disso resulta que a circuncisão masculina adquire contornos bioéticos diferentes se comparados à mutilação genital feminina.

Dentre os povos rurais de alguns países africanos, como o Quênia e a África do Sul, a circuncisão é feita em adolescentes nas escolas de iniciação, as quais incluem jogos em ambientes florestais, montanhosos, dentre outras atividades ${ }^{8}$. 0 procedimento é feito por leigos, com incidência significativa de complicações clínicas, tendo levado o governo da África do Sul a desenvolver políticas não para a erradicação da prática, mas com o objetivo de reduzir os danos à saúde, como, por exemplo, o treinamento de líderes dessas escolas para utilizarem instrumentos adequados em condições mínimas de higiene ${ }^{8}$. Por sua vez, entre os judeus, a circuncisão é prática feita por médicos ao sétimo dia de vida. No caso de bebês prematuros ou doentes, o sétimo dia é considerado a partir da alta hospitalar.

Além dessas práticas relacionadas a rituais culturais ou religiosos, nos Estados Unidos da América (EUA) mais de $70 \%$ dos bebês são circuncidados por médicos, como parte integrante dos cuidados à saúde. Conforme Degregori ${ }^{1}$ destaca, é um tipo de cir- cuncisão aplicada a ampla parcela da população que não é feita por motivações ritualísticas, religiosas ou culturais, mas pautada por 'discursos médicos de verdade'. Para fins comparativos, no Brasil, Korkes et al ${ }^{9}$, com base nos dados do sistema público de saúde, estimam que entre $1,1 \%$ e $5,8 \%$ dos homens tenham sido circuncidados por razões médicas, em algum período da vida. Os mesmos autores registram que em um período de 20 anos (1992 a 2012) houve 63 mortes associadas à internação para circuncisão, mostrando que mesmo quando é um procedimento médico, complicações extremas ocorrem.

Apesar da prática médico-cultural corrente nos EUA, a própria Academia Americana de Pediatria conclui que não há evidências suficientes para sustentar a circuncisão rotineira de bebês, pois possíveis benefícios profiláticos - como evitar infecções urinárias, no bebê, ou proteger contra o HIV, no adulto - não apresentam dados epidemiológicos consolidados. Embora a circuncisão feita no adolescente ou adulto não pareça trazer maiores sequelas a médio prazo (considerando-se que o prepúcio é um órgão naturalmente retrátil), a circuncisão realizada no período neonatal pode se associar à estenose (estreitamento) de uretra, por razões ainda não bem definidas, mas possivelmente em decorrência da alteração da irrigação sanguínea da extremidade do órgão genital ${ }^{1,7,10}$.

Acerca do eventual efeito contra infecções urinárias, Grewal et $a l^{11}$, em extensa revisão, apontam que mais de 110 bebês teriam que ser circuncidados para a ocorrência de apenas um episódio a menos desse agravo de saúde, em comparação aos bebês não submetidos ao procedimento. Os autores também ressaltam que cerca de $3 \%$ a $5 \%$ dos bebês circundados apresentam algum tipo de complicação, sendo os eventos mais leves, como sangramento local ou deiscência de suturas, bem mais frequentes que os graves - emasculação e sepse. Por sua vez, o estudo de Arie ${ }^{10}$ revê o achado que preconizava que a circuncisão protegeria o adulto heterossexual de contrair HIV. Segundo este estudo, o procedimento, no máximo, retardaria o contágio por algum período. Tais hipóteses parecem corroboradas pelo fato de que, no continente africano, mesmo nos países onde se pratica a circuncisão rotineiramente nas escolas de iniciação, é alta a incidência de gestantes soropositivas, atingindo mais de $30 \%$ na África do Sul ${ }^{8}$.

\section{Discussão}

Compreender por que os rituais de mutilação genital feminina e de circuncisão masculina ainda 
persistem nos dias atuais e quais são os valores de ordem moral e cultural que perpetuam esses procedimentos incita reflexões sobre os direitos humanos, e, uma vez que a circuncisão tenha sido medicalizada, sobre a ética médica. Considerando-se que tais práticas são milenares, não é tarefa fácil encontrar dados arqueológicos que esclareçam quais motivos levaram esses povos antigos a instituir tais rituais, mas na literatura médico-científica encontra-se parte do pensamento moral que motiva a adoção desses procedimentos: ao final do século XIX, o cirurgião dr. Sayre, renomado médico da Associação Médica Americana, publicou trabalhos associando a circuncisão à cura de quadros de paralisia aguda ${ }^{1}$.

Em plena era influenciada pela moral vitoriana, o discurso psiquiátrico havia desenvolvido hipóteses da somatização de distúrbios mentais, ou seja, que as desordens mentais seriam causadas por desordens orgânicas. Com finalidades semelhantes, cirurgias genitais femininas foram feitas na tentativa de aliviar sintomas difusos e imprecisos, como cefaleia, histeria, hipersexualidade. Ou seja, do ponto de vista ideológico, segundo Degregori ${ }^{1}$, esse período assinala que os valores associados aos procedimentos genitais são um conjunto de ideias de limpeza/ higiene, e também de controle/modulação/repressão sexual.

São justamente esses valores morais que afloram quando do estudo dos povos nos quais a mutilação genital feminina é rotina. Diniz ${ }^{12}$ acompanhou a história de Tashi, mulher africana que não fora submetida ao ritual de mutilação genital quando jovem e, por isso, era considerada impura, moralmente debilitada e, sobretudo, não pertencente a seu povo. Em outras palavras, o passado renasce no presente nas cicatrizes deixadas nos corpos das jovens, e essa é apenas parte de todo um conjunto de rituais e símbolos que marcam no corpo físico o sinal de um tempo, a passagem, o destino ${ }^{12}$.

O “horror trágico", na definição de Diniz ${ }^{12}$, é justamente a vivência de uma experiência mórbida, desagradável, em decorrência de um fato drástico, profundo, mas que não decorre do infortúnio, do azar, sendo antes de tudo proveniente do cotidiano socialmente instituído. No caso, os rituais de intervenções genitais, os quais, vistos pela ótica dos extremistas do relativismo cultural $^{5}$, não seriam fundamentalmente distintos de outras práticas classificadas pelos antropólogos como rituais de iniciação, como o uso de brincos, tatuagens, alargamento de lábios e orelhas ou outras modificações corporais. Afinal, mesmo a colocação de um simples brinco na orelha pode resultar em complicações infecciosas e morte.
O relativismo cultural, conceito inerente às discussões dos direitos humanos, é um método de abordagem da realidade sensível às diferenças, mas não se pode confundir relativismo cultural com tolerância radical. Como descreve Diniz, os antropólogos direcionaram seus esforços para a demonstração da diversidade, para a compreensão do impossível e, nesse processo, assumiram a bandeira da tolerância como melhor argumento disponível para a existência da diferença. Mas a inquietação causada pelos impossíveis morais trazidos à tona pelos etnógrafos não vem sendo facilmente digerida ${ }^{12}$.

Assim, com base em um relativismo cultural extremo, em nome de mera redução de danos, Degregori ${ }^{1}$ traz à tona que há uma discussão que propõe medicalizar os procedimentos culturalmente criados sobre o corpo feminino. Em nome da redução de sepse, hemorragia e morte, os rituais de remoção do clitóris seriam feitos por médicos, em ambiente hospitalar, mediante assepsia e anestesia - tal como os judeus fazem com os bebês de sete dias de vida. Contudo, a medicalização de uma prática ritual não a isenta de valores e debates de ordem moral.

Os procedimentos médicos apresentam finalidade curativa ou preventiva, sobretudo por seguirem um código de ética no qual o bem-estar, a dignidade, a integridade e a autonomia do paciente são valores essenciais ${ }^{13}$. Um procedimento médico é feito porque o paciente assim o deseja e poderá lhe ser benéfico. Embora muitas intervenções médicas resultem em danos ao paciente, como os casos de mortes relacionadas a circuncisões terapêuticas ${ }^{9}$, no momento em que foram feitas havia a expectativa de um resultado benéfico. No caso da clitoridectomia, não há nem a expectativa nem a chance de um resultado benéfico, mas apenas eventual proteção contra uma prática mais agressiva e em piores condições de higiene. Davis ${ }^{14}$ afirma que nos EUA, na década de 60 , alguns médicos se dispuseram a realizar clitoridectomias em meninas descendentes de somalis, mas ocorreu a promulgação de leis criminalizando a realização de cirurgias genitais que não fossem motivadas por razões terapêuticas.

A circuncisão rotineira de bebês feita por médicos, quer laicos em nome de um programa de saúde, quer judeus em nome da religião, sofre questionamentos bioéticos contundentes. Afinal, se os dados científicos houvessem mesmo provado seu efeito benéfico sobre a saúde, por que não se tornou prática disseminada no mundo, como a vacinação infantil, por exemplo? Svoboda ${ }^{15}$ é contundente ao afirmar que a circuncisão de bebês é um ritual procurando alguma justificativa (preferencial- 
mente médica) para persistir. Benatar e Benatar ${ }^{16}$ apontam que, por um lado, não há razões médicas para a circuncisão rotineira de bebês, mas por outro ponderam que a relativamente baixa incidência de complicações a tornaria um procedimento eticamente aceitável caso os pais decidam por realizá-la. Todavia, Marques et $a l^{17}$, ao discutir o caso da genitoplastia em bebês, apresentam a consideração de que se um procedimento médico não oferecer um benefício direto ao paciente, sua realização é equivocada porque subverte os valores bioéticos ao favorecer vontades da família e da sociedade em detrimento da dignidade da pessoa humana. Assim, para além do prognóstico da intervenção terapêutica, cabe ao médico, pautado no senso bioético e, principalmente, no Código de Ética Médica, priorizar uma conduta prudente, balanceando a autonomia dos pacientes ou seus responsáveis com a responsabilidade médica sobre os eventuais danos provenientes de seus atos.

Waldeck ${ }^{18}$ estudou os motivos tomados pelos pais que submeteram os bebês à circuncisão neonatal e concluiu que, como prática disseminada pelo discurso médico vigente no século XIX, terminou mantendo-se por inércia, isto é, os homens cresceram circuncidados e não vivenciaram maiores sequelas no procedimento, de modo que, de tão prevalente, mesmo sem razões médicas consistentes, transformou-se em norma social. Verificou-se que o simples fato de receber um documento de consentimento informado não promoveu redução na taxa de circuncisões neonatais. Ou seja, é um caso que exemplifica a afirmação de Diniz ${ }^{12}$ que as crenças e as normas sociais não se baseiam no concreto, mas, antes, revestem-se de finalidade em si mesmas.

Assim, os paradigmas e as normas sociais construídas ao redor da circuncisão rotineira de bebês esclarecem aspectos de como e por que os rituais de mutilação genital feminina se tornaram tão arraigados em alguns povos: pela amplitude de pessoas submetidas aos procedimentos, estes permanecem estabelecidos como norma social. Nesse ponto, a tragédia moral é justamente afirmada pelo caráter impossível de solução definitiva dos conflitos morais: uma solução definitiva de um conflito moral implicaria no constrangimento e humilhação de uma das partes do conflito ou, então, uma situação de não solução: ofensa recíproca e insolúvel das partes ${ }^{12}$. Dessa forma, o próprio princípio dos direitos humanos veda o uso de força em nome da defesa desses direitos, pois a força é justamente um meio de promover o aniquilamento físico ou moral de pelo menos uma das partes em conflito ${ }^{5,6}$. Os conflitos morais abrangidos pelos direitos humanos são resolvidos ou pela metamorfose voluntária ou pela docilidade ${ }^{12}$.

A docilidade é simplesmente a aceitação dos valores de um grupo social pelo outro. A metamorfose é provocada por mudanças nas crenças, ou seja, na desilusão. A cultura e, por conseguinte, as crenças não são categorias estanques e imanentes. Não há culturas puras, distintas e perseverantes; elas são híbridas e construídas a partir de diversas fontes, empréstimos, trocas e modificadas pelo simples passar de gerações ${ }^{2}$. Quer dizer, são abertas, sincréticas, instáveis, e só podem ser definidas umas em oposição às outras. Nesse sentido, Steiner et $a l^{5}$ revelam um princípio fundamental na questão do conflito: que uma disputa não é necessariamente direcionada a satisfazer, remediar ou punir um erro, mas sim uma oportunidade de a sociedade rever a complexa cadeia de deveres individuais e coletivos e balancear as demandas contraditórias entre o indivíduo e a sociedade.

\section{Considerações finais}

Waldeck ${ }^{18}$ propõe mudanças nos códigos legais de modo a coibir a circuncisão rotineira feita por médicos. Nesse ponto, é possível aprender com a experiência dos movimentos internacionais em prol da erradicação da mutilação genital feminina: segundo Degregori ${ }^{1}$, a simples proibição legal da prática pode levar a um recrudescimento paradoxal e que o simples fato de constar em um código legal não significa que os governos vão efetivamente se empenhar na mudança de comportamentos socialmente arraigados. Como afirma Segato ${ }^{3}$, uma aplicação superficial do relativismo não esclarece a parcialidade dos pontos de vista e grupos de interesse dentro dos povos, ou seja, não permite visualizar as fissuras, as discordâncias do consenso idilicamente atribuído a culturas dos povos tribais. Por menor seja o grupo, sempre haverá discordâncias e conflitos de interesse. Ao enfatizar esses relativismos internos, os direitos humanos legitimam as dissidências, criando alternativas morais que respeitem as mulheres na decisão de não se submeter a tais práticas mutilantes e que encorajem os médicos a não seguir um procedimento invasivo por simples imitação dos pares ${ }^{3}$.

Concluindo, o combate à mutilação genital feminina perpassa o combate à circuncisão rotineira dos meninos. No momento em que a circuncisão masculina se tornou um ato feito por médicos, a ética médica aponta que, na ausência de dano men- 
surável, não se pode a priori proibir o procedimento cirúrgico. Entretanto, devido ao rol de considerações aqui explicitadas, sobretudo que a circuncisão rotineira feita em meninos não apresenta embasamento na literatura científica, considera-se pertinente que os conselhos profissionais coíbam essas práticas invasivas e potencialmente deletérias aos órgãos e à função sexual dos pacientes adultos do futuro, no intuito de fomentar a necessária mudança cultural em relação ao procedimento. Tal atitude da classe médica pode estimular a conscientização social acerca deste problema, especificamente se, como em outras situações afins, for definida punição ao médico cujo pequeno paciente tenha sofrido complicações decorrentes de uma circuncisão feita sem indicações clínicas adequadas.

Trabalho produzido no Programa de pós-graduação em Bioética da Cátedra Unesco de Bioética e Faculdade de Ciências da Saúde da Universidade de Brasilia (UnB).

\section{Referências}

1. Degregori MCA. Sobre la mutilación genital femenina y otros demonios. Barcelona: Universitat Autònoma de Barcelona; 2001.

2. Sousa BS. Por uma concepção multicultural de direitos humanos. Reconhecer para libertar: os caminhos do cosmopolitismo cultural. Rio de Janeiro: Civilização Brasileira; 2003.

3. Segato RL. Uma agenda de ações afirmativas para as mulheres indígenas do Brasil. Brasília: UnB; 2003.

4. Garrafa V, Azambuja LE. Epistemologia de la bioética: enfoque latino-americano. Rev. Colomb. Bioét. 2009;4:73-92.

5. Steiner HJ, Alston P, Goodman R.. International human rights in context: law, politics and morals. New York: Oxford University Press; 2000.

6. Gott G. Imperial humanitarism: history of an arrested dialectic. In: Hernández-Truyol BE. Moral imperialism: a critical anthology. Nova York: New York University Press; 2002.

7. lasi M. Fimose. Tratado de pediatria. $2^{a}$ ed. São Paulo: Editora Manole; 2010.

8. Organização Mundial da Saúde. Male circuncision: global trends and determinants of prevalence, safety and acceptance. [Internet]. Genebra: WHO; 2007 (acesso maio 2013). Disponível: http:// whqlibdoc.who.int/publications/2007/9789241596169_eng.pdf9

9. Korkes F, Silva JL, Pompeo ACL. Circuncisão por motivos médicos no sistema público de saúde do Brasil: epidemiologia e tendências. Einstein. 2012;10(3):342-6.

10. Arie S. Circuncisão: a divergência nos enfraquece. BMJ. 2010;3(29):532-6.

11. Singh-Grewal D, Macdessi J, Craig J. Circumcision for the prevention of urinary tract infection in boys: a systematic review of randomized trials and observational studies. Arch Dis Child. 2005;90(8):853-8.

12. Diniz D. A antropologia e os limites dos direitos humanos: o dilema moral de Tash. In: Novaes RR, Lima RK, organizadores. Antropologia e direitos humanos. Niterói: EdUFF; 2001.

13. Palhares D, Santos L. Pre-employment medical testing in Brazil: ethical challenges. Indian J Med Ethics. 2012;9(4):266-8.

14. Davis DS. Cultural bias in responses to male and female genital surgeries. Am J Bioeth. 2003;3(2):15.

15. Svoboda JS. Circumcision - a Victorian relic lacking ethical, medical or legal justification. Am J Bioeth. 2003;3(2):52-4.

16. Benatar $M$, Benatar D. Between prophylaxis and child abuse: the ethics of neonatal male circumcision. Am J Bioeth. 2003;3(2):35-48.

17. Marques MGO, Pinto RMO, Faria TM, Viana ACT, Silva FA, Silva SMC et al. Genitoplastia em bebês indianas: encontros e desencontros da medicina, bioética e cultura. Rev. bioét. (Impr.). 2012;20(3):528-37.

18. Waldeck SE. Social norm theory and male circumcision: why parents circumcise. Am J Bioeth. 2003;3(2):56-7.

\section{Participação dos autores}

Dario Palhares e Flávia Squinca, elaboraram e revisaram o trabalho, tendo ambos igual participação no levantamento e análise das referências bioéticas utilizadas.

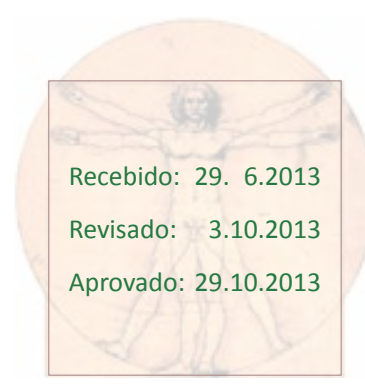

